YAGANG ZHANG, Ph.D.1,2

(Corresponding author)

E-mail: yagangzhang@ncepu.edu.cn

DINGLI QI, M.Sc. ${ }^{3}$

E-mail: qidingli1991@163.com

WEI JIANG, B.Sc. ${ }^{3}$

E-mail: 18634851201@163.com

SHUANG LEI, M.Sc. ${ }^{3}$

E-mail: azumareiji@icloud.com

${ }^{1}$ North China Electric Power University,

State Key Laboratory of Alternate Electrical Power System

with Renewable Energy Sources

Beijing, 102206, P.R. China

2 University of South Carolina, Department of Mathematics

and Interdisciplinary Mathematics Institute

Columbia, SC 29208, United States

${ }^{3}$ North China Electric Power University

Department of Mathematics and Physics

Baoding, 071003, P.R. China
Traffic and Space

Preliminary Communication

Submitted: Oct. 14, 2015

Accepted: Apr. 12, 2016

\title{
OPTIMAL ALLOCATION OF CHANGING STATION FOR ELECTRIC VEHICLE BASED ON QUEUING THEORY
}

\begin{abstract}
Electric vehicle as the main development direction of the future automotive industry, has gained attention worldwide. The rationality of the planning and construction of the power station, as the foundation of energy supply, is an important premise for the development of electric vehicles. In full consideration of the electric demand and electricity consumption, this paper proposes a new construction mode in which charging station and centralized charging station are appropriately combined and presents a location optimization model. Not only can this model be applied to determine the appropriate location for the power station, but it can use the queuing theory to determine the optimal number of power equipment, with which we can achieve the minimum costs. Finally, taking a certain city as an example, the optimum plan for power station is calculated by using this model, which provides an important reference for the study of electric vehicle infrastructure planning.
\end{abstract}

\section{KEY WORDS}

electric vehicle; charging station; centralized charging station; grey system model; queuing theory;

\section{INTRODUCTION}

With the rapid development of the automobile industry all over the world, oil consumption is increasing day by day, even though oil is a non-renewable resource. Besides, with the increase of vehicle exhaust, including poisonous and harmful gas as well as gas with strong heat absorption such as carbon dioxide $\left(\mathrm{CO}_{2}\right)$, a series of environmental problems that threaten human health and life have also appeared [1-4]. Therefore, finding an alternative to oil as a new type of vehicle fuel has become an important research project for the whole world transportation industry and environmental protection department. As a class of new energy vehicles, as well as a fusion of a variety of new technologies, pure electric vehicles, using electricity instead of oil, can effectively solve the problem of energy crisis and environmental pollution with its outstanding characteristics, such as "Zero emissions", no pollution and low noise [5]. Therefore, the promotion of pure electric vehicles, aiming to replace the traditional fuel vehicles, has been recognized by the global automotive industry [6-7].

Obviously, the rationality of the designs of charging station (Battery charging facility) and electrical charging station (Battery replacement facility), the basic service facilities for electric vehicle industry has become an important premise for the comprehensive promotion of electric vehicles [8-10]. A lot of research has been launched. The weight coefficients of the charging station can be determined in consideration of convenience, traffic flow and land prices according to the paper of reference [11]. And using AHP, the weight coefficient of candidate sites can be obtained as the yield coefficient. Thus the optimal model for the maximum operational benefit of charging stations can be also established. The analytic hierarchy process method used in this scheme divides the complex factors affecting the location of the charging station into the relevant ordered levels, making the goals more clear and beneficial to the future research on factors affecting the location of charging stations for electric vehicles. In the research of reference [12], considering 
the layout of the electric vehicle charging station, the planning model is set up to reduce the operation cost of the charging station effectively. The innovation of this project is that the characteristic of the randomness of the charging behaviour of the electric vehicle users has been put forward and the charging load of electric vehicle is considered in the form of regional charging demand. At the same time, under the condition of radial constraint of distribution network, the model established has a reasonable distribution of the electricity demand for the planning area of electric vehicles, and reduces the investment cost of the distribution network. By referring to the idea of dynamic traffic network, a model to minimize the cost of charging stations, meeting the needs of electric vehicle charging is established in the research of reference [13]. In this scheme, the charging time is limited to a certain time, and a two-stage heuristic algorithm is proposed. The method determines the construction area of the target charging station first, so as to determine the scale of the charging station according to the location and the traffic condition and provides the mathematical foundation for further construction of the charging station of the electric vehicle. In the research of reference [14], assuming that the traffic flow of the intersection node indicates the status of traffic flow, the partition of the service range of the charging station is realized by using the weighted Voronoi diagram and a mathematical model is established to minimize the cost of construction operation and the cost of the user's charge loss. In this scheme, the conventional Voronoi diagram is extended, traditional planar location is transformed into three-dimensional space structure and site planning becomes more reasonable in consideration and division of the adjustment of the charging stations of different levels in the service area.

According to most of research on site selection of electric vehicle charging station, although in different literature all kinds of methods to design the construction of charging stations have been used, they all only consider the interests of one party or two party groups, not having developed a plan to meet the needs of multiple interests, and meanwhile, all these studies have certain assumptions, establishing no complete mathematical model. Besides, the development direction of electric vehicle in China is mainly power transfer mode and the charging mode is only used as an auxiliary. Therefore, in comprehensive consideration of the interests of contractors, consumers, municipal planning and other participants, an optimal site selection model for power plant, making centralized charging station and battery replacement station as the overall layout, is established in this paper, aiming to minimize the total social investment cost. Besides, a reasonable model for the process of electricity exchange service is also established using the queuing theory and the optimal number of service facilities can also be decided. Finally, practical examples are carried out to verify the validity of these models.

\section{QUEUING THEORY IN THE APPLICATION OF ELECTRIC VEHICLE CHARGING FACILITIES}

\subsection{Basic principles and components of queuing theory}

The queuing theory (also known as the theory of stochastic service system) originated from a research on the telephone call congestion done by one Danish engineer. Nowadays, the queuing theory has been widely applied to solve transportation, military, service, medical and education problems. Through the analysis of the arrival time of the service object and the service time, we can get the index of the queue length, waiting time and service efficiency, so as to improve the structure of the service system, which can help to meet the needs of the service object, and can make some of the factors in the system reach their best at the same time [15].

The service counter, the queue and the customers are three main components in the queuing theory. The whole system can be simply summarized as when a customer arrives at the reception at a point of time ready to accept some service, the facilities cannot meet the needs of the customer, so that the customer has to wait, following certain rules, due to the service rules or the limits of the number of receptions. Therefore, the purpose of the research of the queue model is to seek the balance between the needs of customers and the scale of service agencies.

\subsection{Queuing theory application in electric vehicle charging system}

The operation process of electric vehicle charging stations can be seen as a queuing service system in which a customer is equivalent to an electric vehicle with the electricity demand, while charging facilities are equivalent to the service counter. When electric vehicle is arriving at a power station, it needs to wait in line to receive services in a certain order if there is no charging facility for free. In the queuing model of the charging station, the stochastic nature of customer electricity demand has already been found in [16-18]. Through the investigation on the law of the demand and offer, we found that the number of electric vehicles arriving at the power station changes with time smoothly, without after-effect, the number is finite and with the typical parameters for the Poisson distribution of $\lambda$ index. At the same time, due to mutual 
independence of time intervals of charging and demand as well as offer, the total service time of the electric vehicle can be simulated according to the negative exponential distribution (of $\mu$ index), and is in line with the service rule, first-come-first-served and the waiting rule.

Therefore, in the electric vehicle charging facilities planning, the standard queuing model of $\mathrm{M} / \mathrm{M} / \mathrm{s}$ indices can be applied to the analysis of the queuing service system for the power station.

\subsection{Queuing model establishment of charging facilities}

Electric vehicle charging system can be achieved by queuing $M / M / s$ model equation.

$$
\begin{cases}\lambda p_{0}=\mu p_{1} & \\ \lambda p_{n-1}+(n+1) \mu p_{n+1}=(\lambda+n \mu) p_{n} & n \leq s \\ \lambda p_{n-1}+s \mu p_{n+1}=(\lambda+s \mu) p_{n} & n>s\end{cases}
$$

where:

$p_{n}$ - probability of $n$-th electric vehicle to accept service;

$s$ - number of facilities that can provide services charge;

$n$ - number of electric vehicles that can accept service;

$\lambda_{m}$ - average arrival rate of electric vehicles of the $m$-th charging station.

$\lambda_{m}=\frac{k_{1} k_{2} D_{m}}{q t}$

where:

$k_{1}$ - average power consumption of electric vehicles;

$k_{2}$ - average mileage of electric cars travelling daily;

$D_{m}$ - ownership of electric vehicles in the planning area where there is the $m$-th station;

$q$ - electric vehicle battery capacity;

$t \quad$ - daily average working hours of charging stations (Daily working time of $m$-th charging station).

The average service rate of electric vehicles to complete the charging process, including pit stop time, leaving time and charging time is noted by $\mu$ :

$\mu=\frac{1}{T_{i / o}+T_{c / h}}$

$T_{i / 0} \quad$ - time required for electric vehicles in and out of the station;

$T_{c / h} \quad$ - average time of electric vehicles accepting service;

$0 \leq n \leq s$ - there are $n$ Electric Vehicles under charging in the system, other service facilities being free; $n>s \quad$ - all the service facilities in service.

The rest of Electric Vehicles waiting for charging.

Using recursive method to solve the differential equation, we can obtain the system state probability.

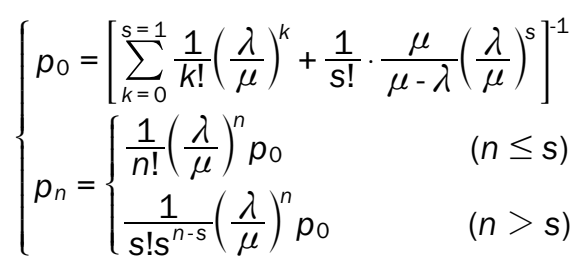

Each operation index in the system is as follows

The service efficiency of charging infrastructure is $\rho$

$\rho=\frac{\lambda}{\mu}$

The utilization rate of charging infrastructure is $\beta$

$\beta=\frac{\lambda}{s \mu}$

The waiting queue length $L_{q}$ and the Mean queue length $L_{\mathrm{s}}$

$\left\{\begin{array}{l}L_{q}=\frac{\rho^{s} \beta p_{0}}{s !(1-\beta)^{2}} \\ L_{s}=L_{q}+\frac{\lambda}{\mu}\end{array}\right.$

Stay within the charging system time $T_{\mathrm{s}}$ and waiting time $T_{q}$

$\left\{\begin{array}{l}T_{s}=\frac{L_{s}}{\lambda} \\ T_{q}=\frac{L_{q}}{\lambda}\end{array}\right.$

In this paper, the average total cost of charging infrastructure system is

$\min F(s)=e_{1} s+e_{2} L_{s}$

where the values are

$e_{1}$ - average time cost of single charging

infrastructure (contains equipment maintenance cost, depreciation cost and manpower cost);

$S$ - number of charging facilities;

$e_{2}$ - average time cost of a single electric vehicle (including electricity consumption, energy costs and travel value).

Therefore, if $s$ is the optimal number of service facilities, then

$\left\{\begin{array}{l}F(s-1)>F(s) \\ F(s+1)<F(s)\end{array}\right.$

Generation into the related parameters

$L_{s}-L_{s+1} \leq \frac{e_{1}}{e_{2}} \leq L_{s-1}-L_{s}$

Solving the inequality, we can determine the optimal number of facility $s$. 


\section{OPTIMAL LOCATION PLANNING MODEL}

\subsection{The precondition of the model}

Plug-in is one of the ways of energy supplement for electric vehicles. Its main mode is to invest in the construction of large-scale charging stations or a large number of charging piles within the planning area, so as to meet the electricity demand of the customers. Large charging stations in the running process produce high discharge power, which has a serious impact on the surrounding users. Dispersible charging piles are difficult to check and manage in the city. Based on the above reasons and considering the advantages of charging stations and charging piles, this paper establishes a model centring on the battery replacement and concentrated charging. Charging stations had been constructed in this paper in the planning area and centralized charging stations were constructed relying on the construction planning of substation (Transformer substation). A large number of scattered stations in the planning area can greatly meet the demand for electricity of electric vehicles. At the same time, a reasonable number of facilities can shorten the waiting time and improve the convenience. Centralized charging stations can make full use of electricity at night to charge the battery as well as the peak suppression, improve the load rate of the power system and optimize power resource.

In July 2010, the Chinese Bureau of Quality and Technical Supervision issued a standardized guidance document: "Electric vehicles power supply and security technical specifications". It provided the classification standard of charging stations, principles of site selection, components of locations, and so on [19]. Therefore, this paper, based on the guidance document standard, in the following charging stations has carried on the strict screening. At the same time, this paper divided the planning area into several small areas according to the nature of land usage. And according to the principle of conservation of regional traffic flow, the number of electric vehicles entering a certain area and leaving the area within a unit time is consistent so it is considered that the number of electric vehicles in each small area is constant. Thus we assume that during the planning period, in electricity the demand point is located in the centre of gravity of each area. The demand forecast for each area depends on the size of total car ownership in urban areas, which is related to the economic development level, path length and other related factors in the planning area [20]. So in the following example, this paper utilizes the relevant data to study the number of electric vehicles in the future through the grey system model $(1, N)$.

\subsection{Model construction}

In this paper, we study the appropriate number of battery replacement stations, so that under the premise of meeting the demand of users, we can get the minimum cost of the total social investment cost $[21,22]$. Therefore, the model is as follows

$$
\begin{array}{ll}
\min & C=C_{1}+C_{2}-C_{3} \\
\text { s.t. } & \sum_{m \in M} Z_{m}=1 \\
& Z_{m n} \leq \sum_{m} x_{n} \quad \forall m \in M, n \in N \\
& \sum_{n} x_{n} \leq 1 \\
& x_{n} \in\{0,1\} \quad \forall n \in N \\
& y_{n g} \in\{0,1\} \quad \forall n \in N, g \in G \\
& z_{m n} \in\{0,1\} \quad \forall m \in M, n \in N
\end{array}
$$

$C_{1}$ - annual maintenance costs and construction costs of charging stations.

$C_{1}=365 \cdot e_{1} t s+\sum_{j=1}^{n} \frac{r_{0}\left(1+r_{0}\right)^{m}}{\left(1+r_{0}\right)^{m}-1} \eta_{j}$

$r_{0}$ - discount rate;

$s$ - number of electric facilities for charging station;

$m$ - service life of the charging station;

$\eta_{j}$ - annual construction costs of the $j$-th charging station;

$\eta_{j}=C_{j}^{T D}+\eta \cdot s_{j}$

$C_{j}^{T D}$ - land cost of the $j$-th charging station (the numerical value is the product of land area and land cost).

$\eta \quad$ - investment cost for single service facility;

$s_{j} \quad$ - number of facilities of the j-th charging station;

$\mathrm{C}_{2}$ - transportation cost;

$$
\begin{array}{r}
C_{2}=365 \cdot\left(\alpha \sum_{m} \sum_{n} H_{m} \cdot z_{m n} \cdot d_{m n}+\right. \\
\left.+\beta \sum_{n} \sum_{g} y_{n g} \cdot d_{n g}\right)
\end{array}
$$

In the formulas above:

$M=\{m\}$ - set of demand point;

$N=\{n\}$ - set of candidate sites (candidate points for electrical charging station);

$G=\{g\}$-set of transformer substation points;

$\alpha, \beta \quad$ - travel costs;

$H_{m} \quad$ - area of demand for battery replacement;

$d_{m n} \quad$ - distance between demanding points $m$ and candidate sites $n$;

$d_{n g} \quad$ - distance between candidate sites $n$ and transformer substation points $g$; 
$C_{3} \quad$ - annual profit of the charging station;

$$
C_{3}=365\left(\gamma_{0}-v\right) q N
$$

$Y_{0} \quad$ - electricity prices in the charging station;

Y - standard commercial electricity prices in the planning area;

$N \quad$ - average daily number of services provided in the charging station (equalling the daily number of electric vehicles needing charging).

The objective function 13 means that within a certain period of time, all the users of Electric Vehicles in the demand point can only receive services from the nearest charging station.

Constraint 14 means the service can be offered to users only when a charging station is located on the candidate site $n$.

Constraint 15 means that one candidate site $n$ can only build one charging station.

Equation 16 means if we build a charging station on a candidate site $n$, then its value is 1 , otherwise its value is 0 .

Equation 17 means if we choose a substation point $g$ as a centralized charging station in a candidate site $n$, then its value is 1 , otherwise its value is 0 .

Equation 18 means if a demand point $m$ is selected to accept services on a candidate site $n$, then its value is 1 , otherwise its value is 0 .

\section{ANALYSIS OF EXAMPLES}

This paper selects a Chinese province city (only focusing on the urban district) as the research object. Obeying the "Electric Vehicle power supply and security technical specifications" and knowing about the related information such as city planning, land price, 27 power station sites and 5 substation sites were selected to meet the requirements.

\subsection{Overview of substation and candidate sites}

The planning of centralized charging station can rely on the location of original substation in the planned area to avoid the influence of power grid distribution factors. Therefore, in the calculation case of this paper, the city's geographical coordinates of the five substations were obtained through the collection of actual data to represent the location of centralized charging stations, as shown in Table 1.
Table 1 - The general situation of substations

\begin{tabular}{||c|c|c||}
\hline \hline \multirow{2}{*}{$\begin{array}{c}\text { Substation } \\
\text { Serial number }\end{array}$} & \multicolumn{2}{|c|}{ Coordinates } \\
\cline { 2 - 3 } & $\mathrm{X}$ & $\mathrm{Y}$ \\
\hline \hline 1 & 25.25 & 100.90 \\
\hline 2 & 36.25 & 21.60 \\
\hline 3 & 68.80 & 45.90 \\
\hline 4 & 50.95 & 43.80 \\
\hline 5 & 58.10 & 9.90 \\
\hline
\end{tabular}

In accordance with the document named "Electric vehicle power supply and protection of technical specifications", 27 candidate sites were selected, meeting the requirements of an electric vehicle charging station, and their geographical features were marked in turn. At the same time, the land prices of candidate sites were also collected into detailed data, which can be seen in Table 2.

Table 2 - Candidate sites coordinates

\begin{tabular}{|c|c|c|c|}
\hline \multirow{2}{*}{ No. } & \multicolumn{2}{|c|}{ Coordinates } & \multirow{2}{*}{$\begin{array}{l}\text { Land prices } \\
\qquad\left[\$ / \mathrm{m}^{2}\right]\end{array}$} \\
\hline & $x$ & $Y$ & \\
\hline 1 & 12.30 & 87.20 & 800 \\
\hline 2 & 34.15 & 103.30 & 850 \\
\hline 3 & 27.25 & 85.90 & 830 \\
\hline 4 & 37.15 & 76.30 & 880 \\
\hline 5 & 50.40 & 93.00 & 850 \\
\hline 6 & 54.65 & 79.50 & 890 \\
\hline 7 & 62.45 & 86.70 & 860 \\
\hline 8 & 19.45 & 65.00 & 900 \\
\hline 9 & 17.05 & 53.10 & 1,100 \\
\hline 10 & 23.80 & 70.80 & 1,200 \\
\hline 11 & 30.55 & 58.10 & 1,300 \\
\hline 12 & 24.10 & 39.80 & 1,250 \\
\hline 13 & 32.80 & 38.20 & 1,250 \\
\hline 14 & 17.88 & 53.10 & 600 \\
\hline 15 & 52.90 & 63.60 & 1,750 \\
\hline 16 & 54.90 & 37.20 & 1,500 \\
\hline 17 & 60.70 & 58.10 & 1,630 \\
\hline 18 & 27.68 & 64.40 & 950 \\
\hline 19 & 30.55 & 27.70 & 830 \\
\hline 20 & 18.52 & 22.40 & 920 \\
\hline 21 & 50.65 & 11.50 & 860 \\
\hline 22 & 60.35 & 23.40 & 930 \\
\hline 23 & 68.90 & 17.30 & 860 \\
\hline 24 & 73.80 & 38.20 & 920 \\
\hline 25 & 80.55 & 24.50 & 860 \\
\hline 26 & 97.90 & 25.50 & 750 \\
\hline 27 & 105.05 & 39.30 & 820 \\
\hline
\end{tabular}




\subsection{Planning of regional economic development and vehicle ownership}

According to the city statistical yearbook from 1997 to 2013 , the regional economic development and vehicle ownership can be obtained, shown in Table 3.

Table 3 - The urban economy and vehicle ownership development

\begin{tabular}{||c|c|c|c||}
\hline Year & $\begin{array}{c}\text { Per capita } \\
\text { Gross Domestic } \\
\text { Product }\end{array}$ & $\begin{array}{c}\text { Road } \\
\text { Length }[\mathrm{km}]\end{array}$ & $\begin{array}{c}\text { Vehicle } \\
\text { ownership }\end{array}$ \\
\hline \hline 1997 & 9,114 & 814 & 49,722 \\
\hline 1998 & 9,793 & 830 & 58,436 \\
\hline 1999 & 10,425 & 859 & 69,634 \\
\hline 2000 & 11,365 & 863 & 82,068 \\
\hline 2001 & 12,157 & 883.7 & 89,550 \\
\hline 2002 & 13,187 & 894.5 & 110,000 \\
\hline 2003 & 15,188 & 925 & 140,000 \\
\hline 2004 & 17,871 & 946 & 170,000 \\
\hline 2005 & 18,670 & 974 & 210,000 \\
\hline 2006 & 20,963 & 1,080 & 250,000 \\
\hline 2007 & 24,243 & 1,150 & 280,000 \\
\hline 2008 & 27,753 & 1,240 & 321,558 \\
\hline 2009 & 30,428 & 1,360 & 410,000 \\
\hline 2010 & 33,462 & 1,475 & 427,657 \\
\hline 2011 & 40,187 & 1,630 & 530,000 \\
\hline 2012 & 43,329 & 1,760 & 593,745 \\
\hline 2013 & 47,666 & 1,980 & 620,000 \\
\hline 2014 & 50,407 & 2,316 & 725,827 \\
\hline
\end{tabular}

\subsection{Other data}

This paper assumes that each electric vehicle battery model and quantity in the model calculations are the same, so that the vehicle battery capacity can be set to $80 \mathrm{KWh}$. At the same time, vehicles from different electrical charging stations to substations road freight are the same, and we set $5 \$ / \mathrm{km}$. When calculating the transportation cost, only the influence of the distance factor is considered. In the example, we assume that the work time of charging stations is 13 hours a day and the payback period is $m=15$ years. This paper assumes that the discount rate $r_{0}$ is 0.1 , electricity price in the city is $0.6 \$ / \mathrm{KWh}$ and electricity price in the charging station is $0.7 \$ / \mathrm{KWh}$. At the same time, we assume that the single electric facilities in charging station cost $\eta=30$ million, ignoring substation capacity size problem and making provisions satisfy the requirements of battery charging network in all respects.

According to the regulation of standard guidance document, the charging stations were divided into three levels, shown in Table 4.

Table 4 - The levels of changing stations

\begin{tabular}{||c|c|c||}
\hline \hline Level & The number of facilities & Floor space $\left[\mathrm{m}^{2}\right]$ \\
\hline \hline 1 & $\geq 25$ & 9.00 \\
\hline 2 & $15-25$ & 4.50 \\
\hline 3 & $\leq 15$ & 2.20 \\
\hline
\end{tabular}

From the current data of basic performance, something concerning electric vehicles can be found; energy consumption of hundreds of kilometres of electric vehicles can be set to $17 \mathrm{KWh}$ and the average daily range is about $200 \mathrm{~km}$. At the same time, according to the factors such as the cost of charging and energy consumption, we can set an average time cost to accept service to $e_{2}=30 \$ / \mathrm{h}$.

In charging stations, each facility's comprehensive time costs as shown in Table 5.

Table 5 - Time cost in changing station $[\$ / h]$

\begin{tabular}{||c|c|c|c||}
\hline $\begin{array}{c}\text { Equipment } \\
\text { maintenance cost }\end{array}$ & $\begin{array}{c}\text { Equipment } \\
\text { depreciation cost }\end{array}$ & $\begin{array}{c}\text { Human } \\
\text { cost }\end{array}$ & $\begin{array}{c}\text { Total } \\
\text { cost }\end{array}$ \\
\hline \hline 42 & 23 & 20 & 85 \\
\hline
\end{tabular}

\subsection{The motor vehicle ownership forecast}

In this paper, on the basis of the original data collection, grey system $\mathrm{G}(1, \mathrm{~N})$ model is used to predict the urban motor vehicle ownership [23]. The prediction method takes into consideration the influencing factors, such as per capita Gross Domestic Product, road length to estimate the ownership of motor vehicles. The corresponding results are shown in Table 6.

As shown in Table 6, in this paper, the vehicle ownership from 1997 to 2014 has been predicted through the grey prediction model and compared with the actual data, showing a significant correlation between them. At the same time, in order to show the matching degree of the data more directly, data from Table 6 have been transformed into the coordinate form, configuring thus Figure 1. 
Table 6 - Predictions of vehicle ownership

\begin{tabular}{||c|c|c||}
\hline \multirow{2}{*}{ Year } & \multicolumn{2}{|c|}{ The motor vehicle ownership } \\
\cline { 2 - 3 } & Real Data & Predicted Value \\
\hline \hline 1997 & 49,722 & 49,722 \\
\hline 1998 & 58,436 & 37,189 \\
\hline 1999 & 69,634 & 53,908 \\
\hline 2000 & 82,068 & 72,940 \\
\hline 2001 & 89,550 & 93,034 \\
\hline 2002 & 110,000 & 116,269 \\
\hline 2003 & 140,000 & 144,444 \\
\hline 2004 & 170,000 & 179,305 \\
\hline 2005 & 210,000 & 212,304 \\
\hline 2006 & 250,000 & 246,649 \\
\hline 2007 & 280,000 & 287,589 \\
\hline 2008 & 321,558 & 337,255 \\
\hline 2009 & 410,000 & 389,390 \\
\hline 2010 & 427,657 & 438,279 \\
\hline 2011 & 530,000 & 510,612 \\
\hline 2012 & 593,745 & 577,623 \\
\hline 2013 & 620,000 & 648,605 \\
\hline 2014 & 725,827 & 719,640 \\
\hline$\vdots$ & $\vdots$ & $\vdots$ \\
\hline 2025 & $\ldots$ & $1,973,992$ \\
\hline
\end{tabular}

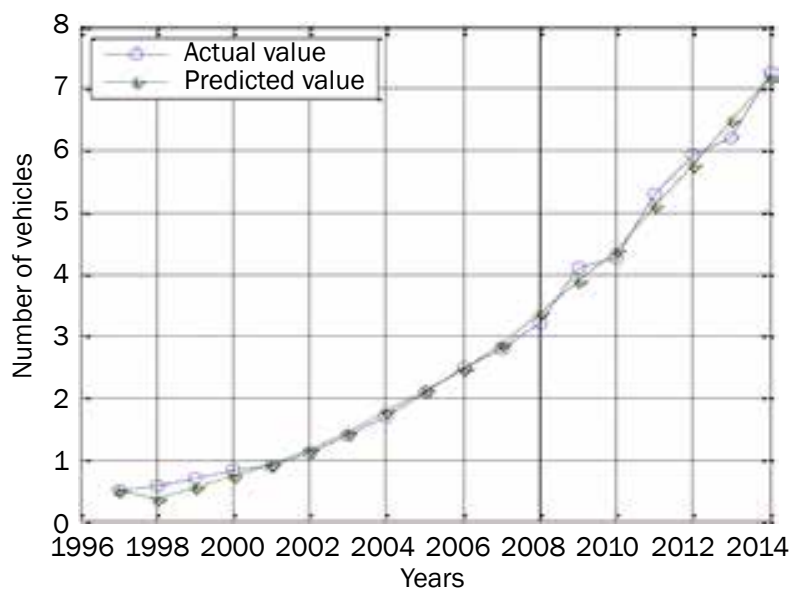

Figure 1 - Vehicle ownership fitting results

The fitting forecast graph of vehicle ownership (Figure 1) shows that GM $(1, \mathrm{~N})$ model of grey system proposed in this paper is consistent with the actual situation, and has great application value. It also provides a good data base for the forecast of electric vehicle ownership.

\subsection{The final optimization results}

In order to rationally design the construction of the power station, the geographical coordinates for power plants and candidate sites of the substations, meeting these conditions were collected under the premise of strictly following the relevant site selection criteria in this case and the planning area is divided according to land use. By using the grey model and the expert forecast data, the electric vehicle ownership in the area can be analyzed, then combining with the theory of queuing system, the size of each power station can be determined. Finally, by using the model with the constraint conditions, the optimal cost can be calculated.

According to the above order, 2025 is considered as the planning year of charging stations. By the grey prediction model we know that in the urban area the number of vehicles has risen to $1,973,992$. According to the document published by the Chinese automotive industry, "Electric Vehicle market forecast report operating situation and investment prospects", by 2025, the Chinese market pure electric vehicle ownership will account for $10 \%$ of the total national motor vehicle. Based on this data, we estimate that the number of Pure Electric Vehicles in the city would be about 197,399 in 2025. At the same time we assume that the number of Electric Vehicles needing to be charged every day accounts for $20 \%$ of the total Electric Vehicles. According to the above model and the related data, we get the minimum the total social investment cost $2.067 \cdot 10^{7}$ dollar. And we get the optimized plan of site selection for charging stations and substations, shown in Table 7 and Figure 2.

Table 7 - Optimized plan of site selection for changing stations in 2025

\begin{tabular}{|c|c|c|c|c||}
\hline \hline $\begin{array}{c}\text { Demand } \\
\text { region }\end{array}$ & $\begin{array}{c}\text { Candidate } \\
\text { sites }\end{array}$ & $\begin{array}{c}\text { Number of } \\
\text { facilities }\end{array}$ & Grade & Substation \\
\hline \hline I & 1 & 7 & 3 & 1 \\
\hline II & 2 & 19 & 2 & 1 \\
\hline III & 5 & 37 & 1 & 1 \\
\hline IV & 7 & 7 & 3 & 1 \\
\hline V & 8 & 19 & 2 & 1 \\
\hline VI & 11 & 37 & 1 & 4 \\
\hline VII & 15 & 37 & 1 & 4 \\
\hline VIII & 17 & 19 & 2 & 3 \\
\hline IX & 19 & 7 & 3 & 2 \\
\hline X & 22 & 37 & 1 & 5 \\
\hline XI & 24 & 19 & 2 & 3 \\
\hline XII & 27 & 7 & 3 & 3 \\
\hline \hline
\end{tabular}

According to Figure 2, the calculation results show that all the candidate site points are close to a substation, so that the total transportation distance can be minimized, and the transportation economy can be improved. At the same time, in the premise of meeting the needs of electric users, the demand points in each partition have chosen the nearest power station, improving the convenience for electric vehicle users. The calculation results of this model further 


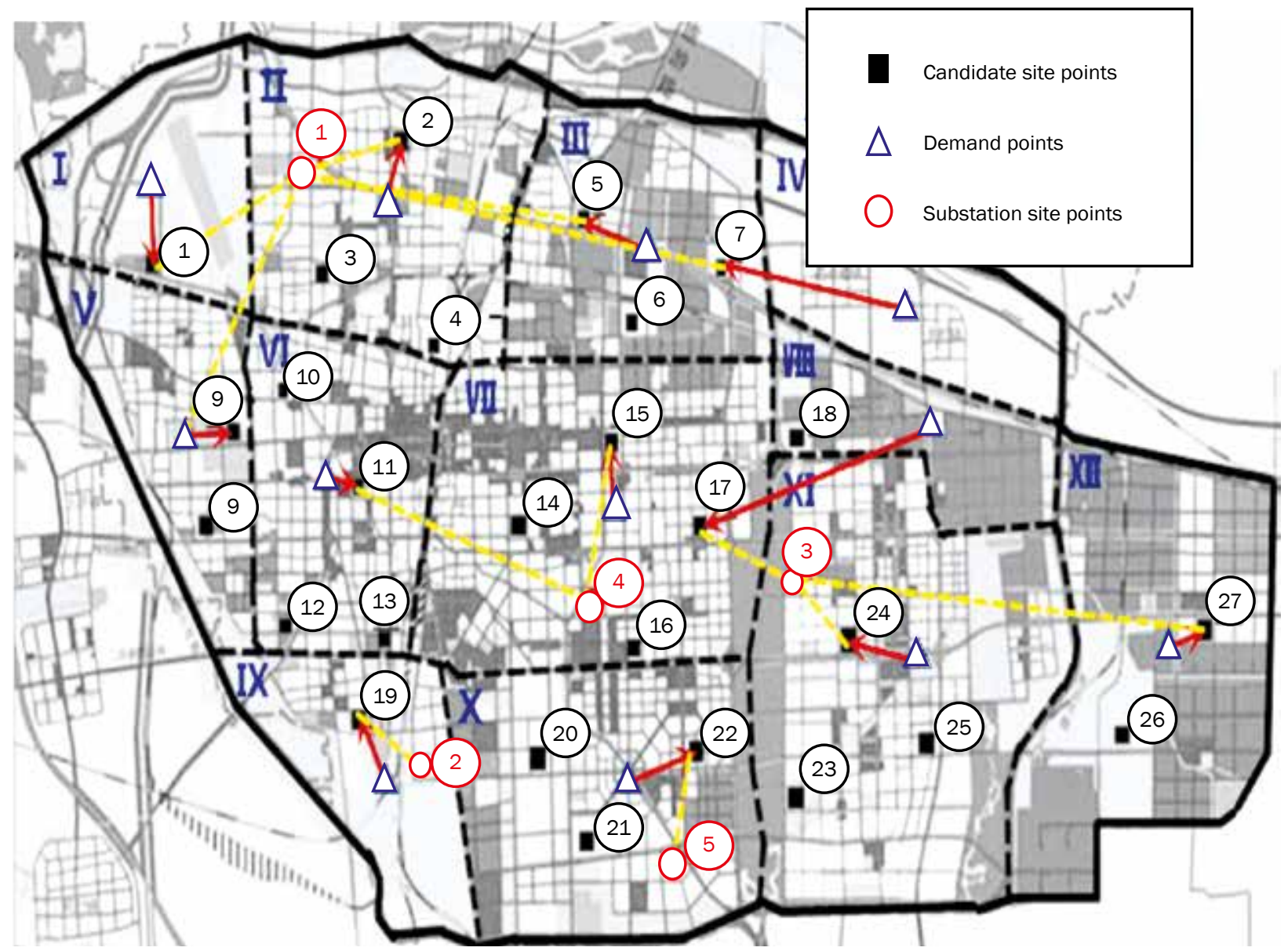

Figure 2 - Optimized location planning of charging stations for the target city in 2025

demonstrate the effectiveness of the proposed optimization model, which has also an important guiding role for the construction of electric vehicle in the planning area.

\section{CONCLUSION}

In this paper, the construction of facilities for charging is planned aiming to minimize the total social investment cost. The optimal number of facilities is calculated by utilizing the method of queuing theory to build the model. The method cannot only satisfy the demand for electric vehicle charging, but it also improves the convenience for users by reducing the waste of resources effectively, so that resources are also used more rationally. Consequently, this study provides an important reference for the research of electric vehicle infrastructure planning. However, there are also some problems in establishing the model, which need to be further studied, such as the following.

In the study of the vehicle ownership forecast by GDP per capita, the total road length is considered to be the influencing factor on the basis of quantitative data. In the actual work, vehicle ownership data are also influenced by some other factors, such as car prices and incomes per capita. Due to the lack of uniform data, the results of this study may also have some limitations. In the future, further reference and improvement need to be made according to the state policies that regulate automotive industry model.

In this study, irrationality may exist on the division of scale of power station and some assumptions of parameter values, resulting from the lack of practical project and reference to relevant national standards. However, with the introduction of more national policies related and accumulation of data, further corrections can be done in the future.

\section{ACKNOWLEDGEMENTS}

This research was supported partly by the National Key Basic Research Project (973 Program) of China (2012CB215200), the NSFC (51637005), the Fundamental Research Funds for the Central Universities (2014ZD43) and the Natural Science Foundation of Hebei Province (G2016502009).

\footnotetext{
张亚刚 ${ }^{1,2}$ ，祁顶立 ${ }^{1}$, 姜炜 ${ }^{1}$, 雷爽 ${ }^{1}$

1 华北电力大学新能源电力系统国家重点实验室 保 定 中国

2 南卡罗来纳大学交叉学科研究中心 哥伦比亚 美国
} 
基于排队论的电动汽车换电站选址规划研究 电动汽车作为未来汽车产业的主要发展方向, 受到 了世界各国的重视。而充、换电站作为电动汽车能 源补给的基础设施, 其规划建设的合理性成为了面 向全球推广电动汽车发展的重要前提。本文充分考 虑电动汽车用户的用电需求与用电行为, 提出了一 种换电站与集中型充电站相结合的建设模式, 并给 出了选址优化模型。该模型不仅可以确定换电站的 站址位置, 还利用排队论的方法, 确定了综合成本 最低时换电站配置换电设施的最佳数量。最后, 以 某城市实际统计数据为例, 运用该模型计算得出该 市内换电站的最佳规划方案, 为研究电动汽车基础 设施规划提供了重要的参考依据。

\section{关键词}

电动汽车; 换电站; 集中型充电站; 灰色系统模 型; 排队论

\section{REFERENCES}

[1] Han SP, Sam P, Marko P. Effect of hydrogen addition on criteria and greenhouse gas emissions for a marine diesel engine. International Journal of Hydrogen Energy. 2014;39(21):11336-11345.

[2] Hakob GA, Elise MH, Suvish M. Effects of vehicle technologies, traffic volume changes, incidents and work zones on greenhouse gas emissions production. Transportation Research. 2014;26(1):10-19.

[3] Zoran L, Eduard M, Rudolf T. The relevance of GHG emissions from motor vehicles. Transactions of FAMENA. 2013;37(2):39-56.

[4] Florian K, Johannes L. Greenhouse gas reduction in transport: analyzing the carbon dioxide performance of different freight forwarder networks. Journal of Cleaner Production. 2015;99(7):177-191.

[5] Chang CC. Advances in Electric vehicles. HKIE transaction. 2014;10(1):1-13.

[6] Song YH, Yang YX, Hu Z. Present status and development trend of batteries for electric vehicles. Power System Technology. 2011;35(4):1-7.

[7] Johannes H, Erik W, Warren S. Comparing the Mass, Energy and cost effects of Lightweighting in conventional and electric passenger vehicles. Journal of Sustainable Development of Energy, Water and Environment Systems. 2014;2(3):284-295.

[8] Lunz B, Sauer DU. Electric road vehicle battery charging systems and infrastructure. Advances in Battery Technologies for Electric Vehicles; 2015.

[9] Paul DL, Jairo V, Robert VP, Arne E. Consumer attitudes about electric cars: Pricing analysis and policy implica- tions. Transportation Research Part A: Policy and Practice. 2014;69(11):299-314.

[10] Amela A. Promoting Environmentally Benign Electric Vehicles. Energy Procedia. 2014;57(3):807-816.

[11] Kou LF, Liu Z, Zhou H. Modeling Algorithm of charging station planning for regional electric vehicle. Modern Electric Power. 2010;27(4):44-48.

[12] Du A, Hu Z, Song Y, Wu JY. Distribution network planning considering layout optimization of electric vehicle charging stations. Power system technology. 2011;2(11):35-42.

[13] Raviv T. The battery switching station scheduling problem. Operations Research Letters. 2012;6(40): 546-550.

[14] Ge SY, Feng L, Liu H. The planning of electric vehicle charging station based on grid partition method. International Conference on Electrical and Control Engineering; 2011.

[15] Li RQ, Su H. Optimal allocation of charging facilities for Electric Vehicles based on queuing theory. Automation of Electric Power Systems. 2011;35(14):58-61.

[16] Wu CY, Li CB, Du L. A method for electric vehicle charging infrastructure planning. Automation of Electric Power Systems. 2010;34(24):36-39.

[17] Tian L, Shi S, Jia Z. A statistical model for charging power demand of electric vehicles. Power System Technology. 2010;34(11):126-130.

[18] Maršanić R, Zenzerović Z, Mrnjavac E. Planning model of optimal parking area capacity. Promet - Traffic \& Transportation. 2010;22(6):449-457.

[19] China. Quality and technical supervision bureau. Electric vehicle power supply and the technical specification - charging stations. DB/11. Beijing: The state council; 2010.

[20] Zhang JY, Yu BY, Makoto C. Interdependences between household residential and car ownership behavior: a life history analysis. Journal of Transport Geography. 2014;34(1):165-174.

[21] Glowacz A, Glowacz A, Glowacz Z. Recognition of thermal images of direct current motor with application of area perimeter vector and Bayes classifier. Measurement Science Review. 2015;15(3):119-126.

[22] Glowacz A. Diagnostics of synchronous motor based on analysis of acoustic signals with the use of line spectral frequencies and k-nearest neighbor classifier. Archives of Acoustics. 2014;39(2):189-194.

[23] Chang X. Guangzhou private ownership based on the GM model prediction and policy recommendations. Market Modernization. 2010;33(5):123-124. 